\title{
Male prairie voles with different avpr1a microsatellite lengths do not differ in
}

courtship behaviour

Brittney M. Graham ${ }^{\mathrm{c} *}$, Nancy G. Solomon ${ }^{\mathrm{a}}$, Douglas A. Noe ${ }^{\mathrm{b}}$, Brian Keane $\mathrm{c}^{\mathrm{c}}$

${ }^{a}$ Department of Biology, Miami University, Oxford, OH 45056, United States

${ }^{b}$ Department of Statistics, Miami University, Oxford, $\mathrm{OH} 45056$, United States

${ }^{\mathrm{c}}$ Department of Biology, Miami University, Hamilton, OH 45011, United States

* Corresponding author: keaneb@miamioh.edu

Keywords:

Anogenital sniffing

Courtship behaviour

Mate choice

Rodents

Voles 


\begin{abstract}
Females are generally expected to be selective whenchoosing their social and sexual partners. In a previous laboratory study, female prairie voles (Microtusochrogaster) showed significant social and sexual preferences for males with longer microsatellite DNA within the avpr1a gene encoding the vasopressin 1a receptor, as predicted if females select mates whose parental behaviour should increase female reproductive success. We tested the hypothesis that males with short versus long avpr1a microsatellite alleles exhibit differences in courtship behavior, which could act as cues for female mate preference. The only behavioural difference we detected between males with short versus long avpr1a microsatellite alleles in mate preference trials was that males with short avpr1a microsatellite alleles sniffed the anogenital region of females more frequently during the first two days of the trials. Our results did not strongly support the hypothesis that a male's avpr1a genotype predicts the courtship behaviourswe measured and suggests thatother courtship behaviours ortraits, such as odour and vocalizations, may be more importantto female prairie voles when choosing mates.Additional studies using a wider array of species are needed to assess the degree to which male mammal courtship behavior provides information on mate quality to females.
\end{abstract}




\section{Introduction}

In most animal species, females are expected to be more selective in choosing mates than males, displayingsocial and sexual preferences for males with particular phenotypes (Kokko et al., 2003; Trivers, 1972). Females may select particularmales because they receivedirect benefits, such asaccess to a high quality territory, protectionfrom predators, or future paternal investment in offspring (Hoezler, 1989; Møller and Jennions, 2001). Females may also choose males thatprovide them with an indirect benefit,such as 'good genes'(Fisher, 1930; Hamilton and Zuk, 1982).Types of benefits from choice of particular males are not mutually exclusive and may have worked in combination in the evolution of traits in mate choice by females.

When choosing a mate, females may be unable to directly assess fitness benefits obtained by mating with a particular male,such as future paternal care. Nonetheless, several models have shown that mate choicecan evolve if femalesuse'indicator'traits that are correlated with the benefits associated with the preferred traits (Michod and Hasson, 1990; Wolf et al., 1997). Numerous empirical studies have documented that females display mating biases based on male variation in morphological traits such as coloration, body size, and body symmetry(Møllerand Thornhill, 1998; Møller and Jennions, 2001 and references therein). These results support the hypothesis that morphological traits can be indicator traits, however, these traits do not always correlate with fitness benefits(Møller and Jennions, 2001). Although not as extensively studied as morphological traits, behaviours, particularly those that occur during courtship, may also serve as indicators of male quality. For example,specific components of courtship behaviourwere correlated with increased paternalbehaviour and hatching of young 
insticklebacks (Spinachiaspinachia; Östlund andAhnesjo, 1998), suggesting that females use these behaviours to select mates.

Rodents do not typically have conspicuous courtship rituals, but the behaviour of males may still provide cues useful in a female's selection of a social or sexual partner.Prior to copulation, males approach females and typically engage inanogenital investigation, which is often followed by mutualnaso-nasal sniffing(Gavish et al., 1983; Gleason and Marler, 2010; Maken and Hennessey, 1999). Other male behaviours that typicallyoccur before copulation include allogrooming of females, sitting next to females,and following andmounting them(Young and Grunt 1951; Ewer 1971; Fernandez-Vargas et al., 2011).

In prairie voles (Microtusochrogaster), most males form a pair bond with one adult female and display social monogamy (Getz et al., 1993).Social partners defend their territory from potentialcompetitors and provide high levels of biparental care (Carter and Getz, 1993; Getz et al., 1993; Solomon, 1993a). However, in natural populations, as well as when maintained in semi-natural enclosures, some males occupy home ranges that overlap with the ranges of multiple females, and these "wanderer" males appear to lack a strong pair bond with a single female (Getz et al., 1993; Solomon and Jacquot, 2002; Streatfield et al., 2011).The continued presence of the female's male partner at the nest postmatingcan significantly increase offspring production, development and survival (Mahady and Wolff, 2002; McGuire et al., 1992; Wang and Novak, 1992). Thus, if a femaleis able to discriminate among males and select a male partner that is likely to remain with herthroughout pregnancy and the rearing of offspring, she could increase heroverall reproductive success. 
Some intraspecific variation in male prairie vole sociosexualbehaviour(e.g. pairbonding) has been attributed to differences in environmental or demographic conditions (e.g., vegetation, adult density,Streatfeild et al., 2011) and individual characteristics (e.g., body size, Chesh et al., 2012). Additionally, neurobiological mechanisms have been found thatinfluence variation in male sociosexualbehaviour(Hammock and Young, 2005; McGraw and Young, 2010).Differences among males in the neural expression of the vasopressin 1a receptor $(\mathrm{V} 1 \mathrm{aR})$ in specific brain regions are correlated with the length of microsatellite DNA within the regulatory region of the gene (avpr1a) encoding the V1aR (Hammock and Young, 2005). Variationin V1aR expression levels within specific regions of the brainappears to affect differences inpartner preference by males and paternal behaviour in laboratory tests (Lim and Young, 2004). Males with longer avpr1a microsatellite alleles display significantly greater partner preference, and lick and groom pups more often than males with shorter avpr1a alleles (Hammock and Young, 2005).These behavioursarecorrelatedwith offspring production and survival (Mahady and Wolff, 2002; McGuire et al., 1992; Wang and Novak, 1992) and suggest a female could maximize her reproductive successby selecting a male with longer avpr1amicrosatellite alleles as a partner because he will be more likely to form a stronger social bond with her and provide greater paternal care.

This hypothesis, that female prairie voles displaysocial and sexual preferences for males with longer avpr1amicrosatellitealleles, has been supported by results of a laboratory partner preference test(Castelli et al., 2011). In these trials, females cannot assess male fidelity and paternal behaviour directly,thus, they must use some indicator trait(s) that correlates with male avpr1a genotype when choosing a partner. However, the 
trait(s) females use to discriminate between males with different avpr1a genotypes has yet to beassessed. Females could use any combination of behavioural, olfactory, and/or auditory cues associated with male avpr1agenotype to discriminate between males. For example, females showed significant mating preferences for males displaying more affiliativebehaviour, but the affiliativebehaviours (male allogrooming and side-by-side contact)were not correlated with male V1aR expression (Ophir et al., 2008).

In our study, wereexamined videotapes from the preference trials conducted by Castelli et al. (2011) to test the hypothesis thatmales with different avpr1a genotypes exhibit differences in courtship behaviour.If female social and sexual preferences for males with longer avpr1amicrosatellite alleles(Castelli et al., 2011) were influenced by male courtship behaviour, we predicted that at least one affiliative, investigatory or agonistic behaviour would differ between males with long versus shortavpr1a microsatellite alleles.

\section{Materials and methods}

\subsection{Ethics statement}

All of the research procedures we used in this study that involved live prairie voles were approved by Miami University's Animal Care and Use Committee (protocol \#689).

\subsection{Subjects}

In 2006 and 2007, we collected prairie voles from natural populations located within the Phillips Tract, University of Illinois, Urbana, IL $\left(40^{\circ} 08^{\prime} 03^{\prime \prime} \mathrm{N}, 88^{\circ} 08^{\prime} 58^{\prime \prime} \mathrm{W}\right)$ 
and the Nelson Environmental Study Area $\left(39^{\circ} 03^{\prime} 07^{\prime \prime} \mathrm{N}, 95^{\circ} 11^{\prime} 32^{\prime \prime} \mathrm{W}\right)$ at the University of Kansas, Lawrence, KS. After collection, we transported all voles to Miami University's animal facilities in Oxford, OHwhere we established separate breeding colonies for the Illinois and Kansas voles. We maintainedvoles under the following conditions: $14: 10 \mathrm{~h}$ light: dark cycle (lights on at $0800 \mathrm{~h}$ ), $19 \pm 1{ }^{\circ} \mathrm{C}$, and $55 \%$ humidity with ad lib food (Rodent Breeder Diet no. 5013, PMI Nutrition International)and water (for details on collection and housing see Castelli et al., 2011).

The Illinois and Kansas breeding colonies were used to generate voles for the female partner preference trials. We genotyped all field-caught voles and their offspring at their avpr1amicrosatellite locus,according to the procedures described in Solomon et al. (2009). For the partner preference trials, we designed a breeding scheme to produce $F_{2}$ males thatpossessed two avpr1amicrosatellitealleles at least one standard error (SE) shorter or longer than the mean allele length,measured in base-pairs (bp), within the population from which the stimulus males descended (Illinois: mean $=743 \pm 3 \mathrm{bp}$; Kansas: mean $=742 \pm 2 \mathrm{bp}$ ). For the trials involving Illinois voles, mean avpr1a microsatelliteallele length was $724.7 \pm 1.9 \mathrm{bp}$ among stimulus maleswe defined as having short avpr1amicrosatellitealleles, and mean avpr1a microsatelliteallele length was 765.7 $\pm 1.8 \mathrm{bp}$ among stimulus males we defined as possessing long avpr1amicrosatellitealleles. The mean allele length among the Kansas stimulus males with short and long avpr1amicrosatellite alleles was $719.7 \pm 1.4 \mathrm{bp}$ and $767.4 \pm 2.4 \mathrm{bp}$, respectively. The breeding scheme weused to generate the $\mathrm{F}_{2}$ stimulus males for the preference trials was designed to maximize the difference in avpr1amicrosatellite allele lengths between males, 
while also uncoupling genes at other loci that might co-segregate with the avpr1a locus and that also couldinfluence partner preference (for details see Castelli, et al., 2011).

All the voleswe used in the preference trials were sexually naïve, $F_{2}$ generation animals, and all individuals within a trial were unfamiliar and unrelated to each other (Castelli et al., 2011). The two stimulus males we selected for each preference trial were derived from the same population as the subject female in each of the trials (either Kansas or Illinois). Females, with the exception of two siblings from Illinois born in separate litters, were unrelated and selected without regard to their avpr1a genotype, since there is no evidence that their vasopressin genotype affects female partner preference (Cho et al., 1999). The stimulus males and subject females were between 38 and 301 days and 45 and 264 days of age, respectively, so all individuals were sexually mature(Solomon, 1991; Mateo et al., 1994). We also controlled for malebody mass to ensure that there were no systematic differences between males with long versus short avpr1amicrosatellite alleles, becausefemalespreferheavier males (Solomon, 1993b; Aschemeier et al., 2008). No vole was used in more than one preference trial.

\subsection{Test apparatus}

We conducted partner preference trials in 60 X 20 X $20 \mathrm{~cm}(\mathrm{~L}$ x W x H) clear Plexiglas arenas divided into three equal sized compartments $(20 \times 20 \times 20 \mathrm{~cm})$ by Plexiglas dividers that had a $3.5 \mathrm{~cm}$ circular opening at the base through which a volecould pass (Castelli et al., 2011). Each compartment was provisioned with processed paper bedding (Cell Sorb Plus, A \& W Products, Inc., New Philadelphia, OH, U.S.A.), and ad libitum food and water.Approximately one day prior to testing, we placed cable- 
tie collars on the necks of the stimulus males. About 1 hour before the start of a trial,we tethered astimulus male in each of the end compartments of the arena to allow them to become acclimated to the testing apparatus. Males were tethered using a fishing leader (Panduit Corp., Tinley Park, IL, U.S.A.)attached to the cable-tie collar and the wirescreen lid on the top of the arena via a swivel clip.The two stimulus males were always from the same population with one male possessing two long avpr1a microsatellite alleles and the othertwo short avpr1a microsatellite alleles. Stimulus males could freely move within their own compartment but could not leave the compartment in which they were tethered. This prevented male-male interactions from influencing female preference. Male avpr1a microsatellite allele length was counterbalanced to prevent position effects.

\subsection{Behavioural assay}

We conducted the trials in a room isolated from the breeding colony rooms with a separate airflow and with the same photoperiod, humidity, and temperature as the breeding colony (Castelli et al., 2011).During the lights off portion of the light cycle, the arena and voles were illuminated with red light bulbs mounted on the ceiling.

At the start of each preference trial $(N=16$ for Illinois voles; $N=16$ for Kansas voles), we placed females in the central compartment and they were free to roam in all three compartments during the trials. All preference trials lasted $72 \mathrm{~h}$ and were videotaped using a time-lapse VCR at either $0.2 \mathrm{~s}$ intervals (Panasonic AG-TL950) or 0.6 s intervals (Panasonic AG-6040; Castelli et al., 2011).A 72-h duration for the trials was selected because a previous preference trial using sexually naïve prairie voles found that $52 \mathrm{~h}$ was the median time foranoestrus females to reach oestrus and mate (Witt et al., 
1988). After each trial, arenas were cleaned with water and Quatricide (Pharmacal Research Laboratories, Inc., Waterbury, CT, U.S.A.) and subsequently rinsed with 70\% ethanol.

To evaluate the behaviour of males, we randomly selected one 30-minperiod from each light and dark periodfrom each $\operatorname{day}(N=\operatorname{six} 30$-min periods per trial $)$. In each period, we recorded the number of separate occurrences of naso-nasal sniffing and anogenital sniffing by males. We recorded the duration of side-by-side contact, allogrooming by males, active exploratory contact by males (male climbing on, sniffing anywhere other than naso-nasal and anogenital, and/or mounting the female), and male recipient of exploratory contact (allowing the female to climb on and/or sniff the body of the male). Aggression was originally included in the list ofbehaviours recorded but it occurred so rarely $(0.30 \pm 0.12[\overline{\mathrm{x}} \pm \mathrm{SE}]$ bouts of aggression per trial) that it was eliminated from analyses. We recorded durationof behaviour only if a single bout exceeded 10 seconds. If a behaviour was interrupted by a different behaviour or if 5 seconds elapsed between performing the same behavior, we scored this as a new bout of the same behavior. The observer (BMG) was blind to the avpr1a microsatellite allele lengths of malesuntil after all videotapes werescored.

\subsection{Statistical analysis}

For each trial, we summed thenumber of bouts or duration of each behaviour separately for the male with long versus short avpr1a microsatellite allelesduring each of the six 30-min observationperiods. Because the amount of time that a female spent with a male could influence the frequency or duration of behaviourswith a specificmale, we 
divided the number of bouts or duration of each behaviour by the total amount of time the female spent in the compartment of that male during a particular observation period. We then used these ratios (number of bouts or duration/total time in male compartment)to calculatea difference score for eachbehaviour during each 30-min period of a trial by subtracting the ratio observed in the male with the long avpr1a microsatellite alleles from that observed in the male with the short avpr1a microsatellite alleles. The difference scores between the short allele value and the long allele value (Short-Long)for each trial were analyzed using a repeated-measures ANOVA in JMP Pro 11.2.0. Population (Kansas or Illinois), period (1=Day1Light, 2=Day1Dark, 3=Day2Light, 4=Day2Dark, 5=Day3Light, 6=Day3Dark), population* period, and TrialID nested within population (random effect) were the factors incorporated into the analysis. After the analyses were completed, we adjusted the rejection criteria foreach comparison using a sequential Bonferroni adjustment, with $\alpha$ initially equal to 0.05 , to reduce the probability of committing a Type I error due to conducting multiple comparisons.

\section{Results}

There were no differences between voles from Kansas versus Illinois in any of the behaviours we measured (all $P>0.05$ ), so we removed population and the interaction with populationas factorsin the models. Males with short versus long avpr1amicrosatellite allele lengths did not differ in any behaviour except anogenital sniffing $\left(F_{(5,155)}=4.24, P=0.0012\right.$, sequential Bonferroni adjusted $P=0.0083[0.05 / 6]$; Table 1). Males with short avpr1a microsatellites sniffed the genital region of females significantly more often than did males with long avpr1a microsatellites during light 
period of days one and two of the 72-h trials (Fig. 1). The frequency of anogenital sniffing during the other time periods was indistinguishable from the dark period on day three.

\section{Discussion}

The results of our study do not strongly support the hypothesis that males with different avpr1a genotypes exhibit differences in courtship behaviour and that a male's courtship behaviour is indicative of his avpr1a genotype. The only difference that we found inthe behaviourof males with different avpr1amicrosatellite allele lengths was in anogenital sniffing during the first two lights-on periods of the trials. Males with short avpr1a microsatellites sniffed females more often than did males with long avpr1a microsatellites, suggesting that initially males with the short avpr1amicrosatellite alleles spent more time investigating unfamiliar females.Our result is consistent with the finding that males with shorter avpr1a microsatellite alleles display greater interest in novel females relative to males with longer avpr1a microsatellite alleles (Hammock and Young, 2005).Since male rodentscan useanogenitalor vaginal odors to assess the species, sex and reproductive condition of females (Johnston, 2003; delBarco-Trillo et al., 2009), males with shorter avpr1a microsatellite alleles may take longer to make these assessments or are being more cautious before engaging in the next phase of courtship.

In Castelli et al. (2011), femaleswere sexually naïve and displayed a significant mating bias toward males that engaged in less anogenital sniffing. Since oestrus is induced in prairie voles, females need to come into physical contact with chemical cues from an unfamiliar adult male to become reproductively activated (Carter et al., 1980). 
Females can come into contact with the necessary chemical cues through anogenital sniffing the unfamiliar male when males and females engage in mutual anogenital sniffing. Females could perceive excessive anogenital sniffing as a type of harassment or they could be ready for males to progress to the next step in courtship.Females may also take longer to become behaviorally receptive when courted by males with short avpr1a microsatellite alleles.

None of the other behaviours we measured differed between males with different avpr1a genotypes, suggesting that these behavioursdid not influence female mate selection. In a similar preference test by Ophir et al. (2008), females were significantly more likely to mate with males that groomed the females more and spent more time in side-by-side contact with females, but the neural expression of $\mathrm{V} 1 \mathrm{aR}$ in five regions of male brains was not correlated with these behaviours. In our study we found that these same two behaviours were not different between males with long versus shortavpr1amicrosatellite alleles. There were some differences in the methods used in these two studies that could explain the inconsistencies in the results between them. For example, in Ophir et al.'s (2008) study, females had been exposed tosoiled male bedding and thus, may have already been in oestrus by the time the trials started, and all males were sexually experienced. These differences may have altered the behaviour of males and females, as well as whichbehaviours females preferred in these studies. Although the studies differ in regards to the role that affiliativebehaviourscan play in mate choice, both studies indicate that neither male avpr1a genotype nor V1aR neural density was related to variation in these two particular affiliativebehaviours. 
The results of the Castelli et al. (2011) study are consistent with the hypotheses that females show social and sexual preferences for males with long avpr1a microsatellite alleles because the behaviour of these males should increase female reproductive success. However, the phenotypic cues females used to discriminate among males with different avpr1a genotypes during mate selection remain unidentified. One interpretation of our results and those of Ophir et al. (2008) is that male behaviour may not be the primary cue used by females to discriminate among males with different avpr1 genotypes.

Alternatively,females may beassessing subtleraspects of the behaviours we measured or are influenced by male behaviours that were not measured in these studies.

Olfactory cues are important in mate selection by female rodents (Roberts, 2007); some studies suggest that they mayfunction to allow females to recognize males of the correct species (e.g., eastern chipmunks, Tamiasstriatus,Keevin et al., 1981), sex of the scent donor, if they have a compatible genotype (e.g., house mice, Musmusculus, Potts et al., 1991), and whether scent donors are kin, are dominant, or are territory holders(Ropartz, 1977; Halpin, 1986; Tregenza and Wedell, 2000). Male and female prairie voles can distinguish among conspecifics using odour cues, and these cues can influence behaviours such as nest building (Newman and Halpin, 1988). However, there is no empirical evidence demonstrating that male avpr1a genotype is correlated with differences in odour cues, or that females can discriminate among males on the basis of these odour differences.

Some rodents use audible or ultrasonic vocalizations (USVs) in mate choice (Clutton-Brock and McAuliffe, 2009; Fernandez-Vargas et al., 2011; Monticelli andAdes, 2013; Musolf et al., 2010).Adult male prairie voles produce significantly moreUSVs than 
females and these calls may be important in attracting mates since males produce more calls in response to unfamiliar females than to female siblings or conspecific males (Lepriet al., 1988; Ma et al., 2014). The male calls are also more structurally complex relative to female calls and could be used to transmit information about male quality (Lepri et al., 1988; Ma et al., 2014).

In socially monogamous mammals that exhibit biparental care, females mayuse phenotypic cues indicative of mate fidelity and parental behavior when selecting a mating partner(Hoelzer, 1989). In rodents, there isevidence that males produce olfactory cues and vocalizations that convey information about male quality (Roberts, 2007; Musolf et al., 2010); females respond selectively to these cues.Males investigate females before attempting to mount them and may engage in courtship behavior such as seen in the rumba movements (hip-swaying) of the male guinea pig, which is often accompanied by purring or rumbling vocalizations (King, 1956; Cohn et al., 2004). However, it is not clear whether the behavior alone, the vocalizations alone or a combination of the two cues provide the best information to conspecific females. A growing number of studies indicate that females of some species use multiple cues when selecting a mate (Candolin, 2003). If malecourtship behavior is an honest indicator of the males' quality, these behaviorscould also be a target of sexual selection. Additional studies using a wider array of speciesare needed to assess the degree to whichmale mammalsdisplay courtship behavior that provides information to females that is not provided by auditory or olfactory cues or whether courtship behavior reinforces the information provided by other sensory modalities. 


\section{Acknowledgements}

We thank Dean Kettle and Steve Buck for providing logistical support at the Kansas University and University of Illinois field sites. Funding for this study was provided by the National Science Foundation (IOS-0614015 to BK, and NGS), and a Howard Hughes summer internship (BG) from Miami University. The content of this paper is solely the responsibility of the authors and does not represent the official views of the National Science Foundation or Miami University.

\section{References}

Aschemeier, L.M., Keane, B., Solomon, N.G., 2008. Body size has a greater influence on female mate choice than length of microsatellite region of the avpr1a gene in male prairie voles. Journal of Young Investigators, 18, published online 25 February 2008. www.jyi.org/research/re.php?id 1447.

Candolin, U., 2003. The use of multiple cues in mate choice. Biol. Rev. 78, 575-595.

Carter, C.S.,Getz, L.L.,Gavish, JL McDermott J.L., Arnold, P., 1980. Male-related pheromones and the activation of female reproduction in the prairie vole (Microtusochrogaster). Biol. Reprod. 23, 1038-1045.

Carter, C.S.,Getz, L.L., 1993. Monogamy and the prairie vole. Sci. Am. 268, 100-106.

Castelli, F.R., Kelley, R.A., Keane, B., Solomon, N.G., 2011. Female prairie voles show social and sexual preferences for males with longer avpr1a microsatellite alleles. Anim. Behav. 82, 1117-1126. 
Chesh, A.S., Mabry, K.E., Keane, B., Noe, D.A., Solomon, N.G., 2012. Are body mass and parasite load related to social partnerships and mating in Microtusochrogaster? J. Mammal. 93, 229-238.

Cho, M.M., Devries, A.C., Williams, J.R., Carter, C.S.,1999. The effects of oxytocin and vasopressin on partner preferences in male and female prairie voles (Microtusochrogaster). Behav.Neurosci. 113, 1071-1079.

Clutton-Brock, T., McAuliffe, K.,2009. Female mate choice in mammals. Q. Rev. Biol. $84,3-27$.

Cohn, D.W.H., Tokomaru, R.S., Ades, C. 2004., Female novelty and the courtship behavior of male guinea pigs (Caviaporcellus). Braz. J. Med. Biol. Res. 37, 847-851. delBarco-Trillo, J., LaVenture, A.B., Johnston, R. E., 2009. Male hamsters discriminate estrous state from vaginal secretions and individuals from flank glands. Behav. Proc. $82,18-24$.

Ewer, R.F., 1971. The biology and behaviour of a free-living population of black rats (Rattusrattus). Anim. Behav. Monographs 4, 125-174.

Fernández-Vargas, M., Tang-Martínez, Z., Phelps, S.M., 2011. Singing, allogrooming, and allomarking behavior during inter- and intra-sexual encounters in the Neotropical short-tailed singing mouse (Scotinomysteguina). Behaviour 148, 945-965.

Fisher, R.A., 1930. The Genetical Theory of Natural Selection. Oxford Clarendon Press, Oxford.

Gavish, L., Carter, C. S., Getz, L.L., 1983. Male-female interactions in prairie voles. Anim. Behav. 31, 511-517. 
Getz, L.L., McGuire, B., Pizzuto, T., Hofmann, J., Frase, B., 1993. Social organization of the prairie vole, Microtusochrogaster. J. Mammal. 74, 44-58.

Gleason, E.D., Marler, C. A., 2010. Testosterone response to courtship predicts future paternal behavior in the California mouse, Peromyscuscalifornicus. Horm. Behav. 57, $147-154$.

Halpin, Z.T., 1986. Individual odors among mammals: origins and functions. Adv. Study Behav. 16, 39-70.

Hamilton, W.D., Zuk, M., 1982. Heritable true fitness and bright birds: a role for parasites? Science 218, 384-387.

Hammock, E.A.D., Young, L.J.,2005. Microsatellite instability generates diversity in brain and sociobehavioral traits. Science 308, 1630-1634.

Hoelzer, G.A., 1989. The good parent process of sexual selection. Anim. Behav. 38, $1067-1078$.

Johnston, R.E., 2003. Chemical communication in rodents: from pheromones to individual recognition. J. Mammal. 84, 1141-1162.

Keevin, T.M., Halpin, Z.T., McCurdy, N. 1981. Individual and sex-specific odors in male and female eastern chipmunks (Tamiasstriatus). Biol. Behav. 6, 329-338.

King, J.A., 1956. Social relations in the domestic guinea pig living under semi-natural conditions. Ecology. 37, 221-228.

Kokko, H., Brooks, R., Jennions, M.D., Morley, J., 2003. The evolution of mate choice and mating biases. Proc. R. Soc. Lond. B 270, 653-664.

Lepri, J.J., Theodorides, M.,Wysocki, C.J., 1988. Ultrasonic vocalizations by adult prairie voles, Microtusochrogaster. Experimentia 44, 271-273. 
Lim, M.M., Young, L.J., 2004. Vasopressin-dependent neural circuits underlying pair bond formation in the monogamous prairie vole. Neuroscience, 125, 35-45.

Ma, S.T., Resendez, S.L.,Aragona, B.J., 2014. Sex differences in the influence of social context, salient social stimulation and amphetamine on ultrasonic vocalizations in prairie voles. Integr. Zool. 9, 280-293.

Mahady, S., Wolff, J.O., 2002. A field test of the Bruce effect in the monogamous prairie vole, Microtusochrogaster. Behav. Ecol. Sociobiol. 52, 31-37.

Maken, D. S., Hennessey, M. B., 1999. Rehousing periadolescent male guinea pigs (Caviaporcellus) apart from their mothers for 24 hours increases maternally directed sexual behavior and plasma testosterone. J. Comp. Psychol. 113, 435-442.

Mateo, J.M., Holmes, W.G., Bell, A.M., Turner, M., 1994. Sexual maturation in maleprairie voles: effects of the social environment. Physiol. Behav. 56,299-304.

McGraw, L.A., Young, L.J., 2010. The prairie vole: an emerging model organism forunderstanding the social brain. Trends Neurosci. 33, 103-109.

McGuire, B., Russell, K.D., Mahoney, T., Novak, M., 1992. The effects of mate removal on pregnancy success in prairie voles (Microtusochrogaster) andmeadow voles (Microtuspennsylvanicus). Biol. Reprod. 47, 37-42.

Michod, R.E., Hasson, O.,1990. On the evolution of reliable indicators of fitness. Am. Nat. $135,788-808$.

Møller, A.P., Thornhill, R., 1998. Bilateral symmetry and sexual selection: a metaanalysis. Am. Nat. 151, 174-192.

Møller, A.P., Jennions, M.D., 2001. How important are direct fitness benefits of sexual selection? Naturwissenschaften $88,401-415$. 
Monticelli, P.F.,Ades, C., 2013. Bioacoustics of domestication: alarm and courtship calls of wild and domestic cavies. Bioacoustics 20, 169-192.

Musolf, K., Hoffmann, F., Penn, D.J., 2010. Ultrasonic courtship vocalizations in wild mice, Musmusculus. Anim.Behav. 79, 757-764.

Newman, K.S.,Halpin, Z.T., 1988. Individual odours and mate recognition in the prairie vole, Microtusochrogaster. Anim.Behav. 36, 1779-1787.

Ophir, A.G., Crino, O.L., Wilkerson, Q.C., Wolff, J.O., Phelps, S.M., 2008. Femaledirected aggression predicts paternal behavior, but female prairie voles prefer affiliative males to paternal males. Brain Behav. Evol. 71, 32-40.

Östlund, S., Ahnesjö, I., 1998. Female fifteen-spined sticklebacks prefer better fathers. Anim. Behav. 56, 1177-1183.

Potts, W.K., Manning, C.J., Wakeland, E.K., 1991. Mating patterns in seminatural populations of mice influenced by MHC genotype. Nature 352, 619-621.

Roberts, S. C., 2007. Scent marking. In: Wolff, J.O., Sherman, P.W. (Eds.), Rodent Societies. University of Chicago Press, Chicago, pp. 255-266.

Ropartz, P., 1977. Chemical signals in agonistic and social behavior of rodents. In:Müller-Schwarze, D., Mozell, M.M., (Eds.),Chemical Signals in Vertebrates. Plenum Press, New York, pp. 169-184.

Solomon, N.G., 1991. Age of pairing affects reproduction in prairie voles. Lab. Anim. $25,232-235$.

Solomon, N.G., 1993a. Comparison of parental behavior in male and female prairie voles, Microtusochrogaster. Can. J. Zool, 71, 434-437. 
Solomon, N.G., 1993b. Body size and social preferences of male and female prairie voles, Microtusochrogaster. Anim. Behav. 45, 1031-1033.

Solomon, N. G., Jacquot, J. J. 2002. Characteristics of resident and wandering prairie voles, Microtusochrogaster. Can. J. Zool, 80, 951-955.

Solomon, N.G., Richmond, A.R., Harding, PA, Fries, A., Jacquemin, S., Schaefer, R.L., Lucia, K.E., Keane, B., 2009. Polymorphism at the avpr1a locus in male prairie voles correlated with genetic but not social monogamy in field populations. Mol. Ecol. $18,4680-4695$.

Streatfeild, C.A., Mabry, K.E., Keane, B., Crist, T.O., Solomon, N.G., 2011 Intraspecific variability in the social and genetic mating systems of prairie voles Microtusochrogaster. Anim. Behav. 82, 1387-1398.

Tregenza. T., Wedell, N., 2000. Genetic compatibility, mate choice and patterns of parentage: invited review. Mol. Ecol. 9, 1013-1027.

Trivers, R.L., 1972. Parental investment and sexual selection. In: Campbell, B. (Ed.), Sexual Selection and the Descent of Man 1871-1971. Aldine, Chicago, pp. 136-179. Wang, Z.X., Novak, M.A., 1992. The influence of the social environment on parental behavior and pup development of meadow voles (Microtuspennsylvanicus) and prairie voles (Microtusochrogaster). J. Comp. Psychol. 106, 163-171.

Witt, D.M., Carter, C.S., Carlstead, K., Read, L.D., 1988. Sexual and social interactions preceding and during male-induced oestrus in prairie voles, Microtusochrogaster. Anim. Behav. 36, 1465-1471.

Wolf, J.B., Moore, A.J., Brode III, E.D., 1997. The evolution of indicator traits for paternal quality: the role of maternal and paternal effects. Am. Nat. 150, 639-649. 
Young, W.C., Grunt, J.A., 1951. The pattern and measurement of sexual behavior in the male guinea pig. J. Comp. Physiol. Psychol. 44, 492-500. 


\section{Table 1}

Results of repeated measures ANOVA to examine the effects of the length of the avpr1a microsatellite alleleand time on male prairie vole (Microtusochrogaster) behaviouralresponses in a choice test ( $N=32$ trials). Table contains the $P$-values for the main effects of allele length (difference scores between the short allele value and the long allele value; Short-Long)and period.

Behaviour

Naso-nasal sniffing

Anogenital sniffing by male

Side by side contact

Allogrooming by male

Active exploratory contact by male

Male recipient of exploratory contact
Short-Long

0.274

0.309

0.081

0.286

0.038

0.056
Period
0.567

$0.001 *$

0.314

0.407

0.141

0.102

* The asterisk indicates that there is a significant difference after using a sequential Bonferroniadjustment $(P=0.0083)$, with $\alpha$ initially equal to 0.05 . 


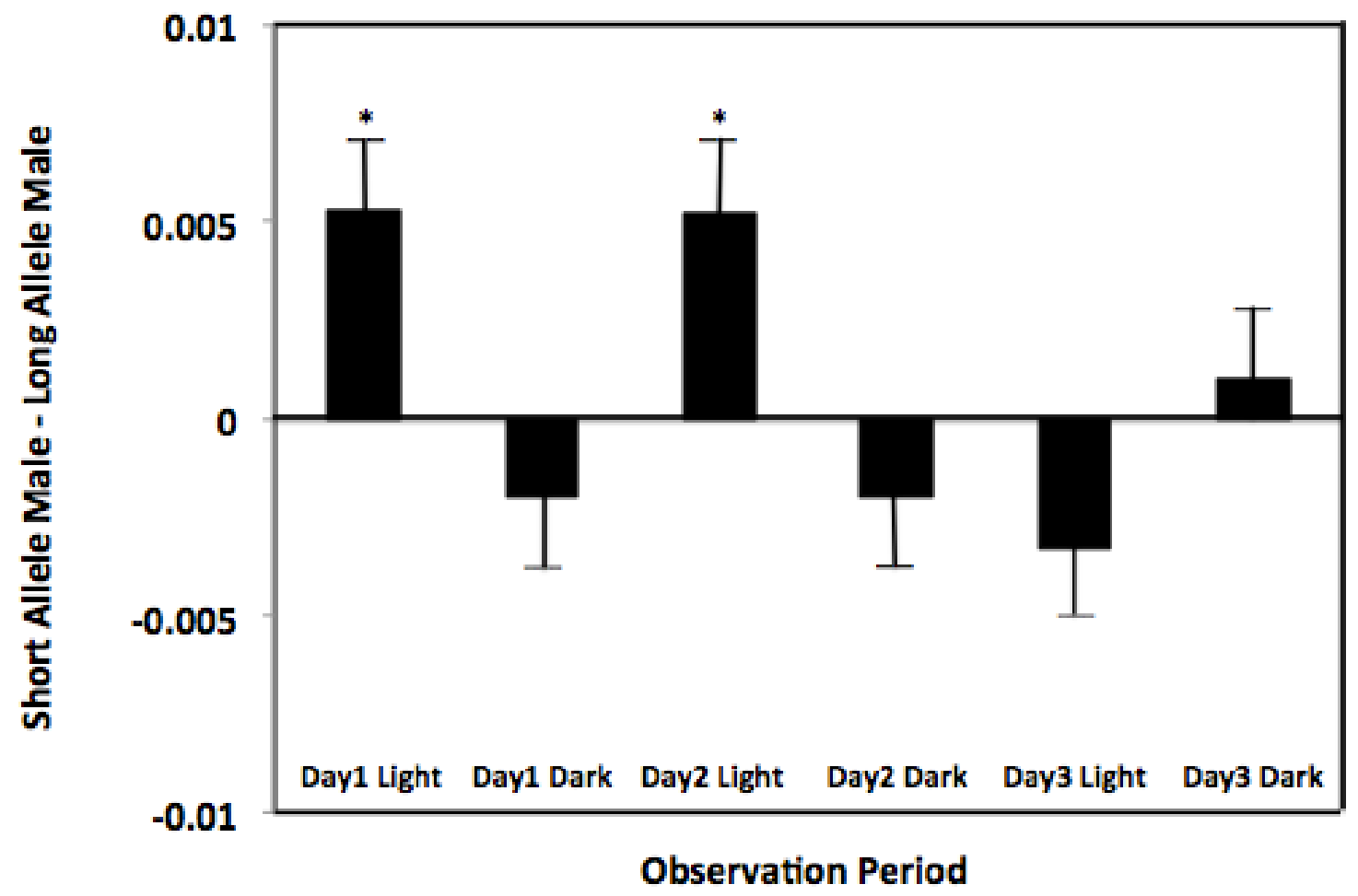

Fig. 1. Mean difference scores $(+\mathrm{SE})$ for the frequency of male anogenital sniffing behaviourby male prairie voles (Microtusochrogaster) during each of the six observation periods during the 72-h trial $(N=32$ trials). Difference scores for a period were calculated by dividing the number of bouts ofanogenital sniffing for a particular male by the time the female spent in the male's compartment and subtracting the ratio observed in the male with the long avpr1a microsatellite alleles from that observed in the male with the short avpr1a microsatellite alleles. * indicates a significant difference in anogenital sniffing compared to the last observation period (Day3 Dark). 